certain elements significantly related to outcome in the United States (malignancy and previous admission to intensive care) do not seem to be important factors in the United Kingdom and Irish cohort. Finally, interobserver variations remains a significant potential source of error, which may have profound effects on calculated probabilities of survival. ${ }^{13}$

Where does this leave audit of intensive care? The Intensive Care Society's APACHE II studies and others tell us that scoring systems predict the risk of a particular outcome: they do not predict the outcome for a particular patient, and they cannot be used as a substitute for clinical judgment. For example, a predicted risk of death of $50 \%$ identifies a critically ill population, but it also tells us that for any patient within that mortality band the outcome could not be more uncertain. Similarly, scoring systems may show comparative performance between groups of intensive care units, but they cannotbe used to make judgments about single units in isolation.

The United Kingdom Intensive Care Society has recently established a national centre for audit and research, one of whose functions should be to develop reliable measures of case mix which would take into account temporal changes or regional differences in resources, population health, or treatments. This important initiative provides a unique opportunity to establish a national database for intensive care, as well as links with other European countries. Most intensivists will want to contribute to it provided that support for collection of data, confidentiality, and ownership of data can be assured and that assessment of performance is conducted in the spirit of constructive scientific inquiry.

A useful starting point for the centre would be to investigate the high mortality after discharge from intensive care described in the Intensive Care Society's APACHE II study, a surplus mortality for individual units of $6-16 \%$ or a total of 860 people. Why are these patients dying on the wards? Did pressure on beds precipitate premature discharge from intensive care? Were no high dependency facilities available? Was admission to intensive care inappropriate? Whatever the reason, it represents an important additional waste of lives and resources.

JULIAN BION

College and Association of Anaesthetists' senior lecturer in intensive care medicine

Queen Elizabeth Hospital,

Birmingham B15 2TH

1 Rowan KM, Kerr JH, Major E, McPherson $\mathrm{K}$, Short A, Vessey MP. Intensive Care Society's APACHE II study in Britain and Ireland. I: Variations in case mix of adult admissions to general intensive care units and impact on outcome. $B M 7$ 1993;307:972-6.

2 Rowan KM, Kerr JH, Major E, McPherson K, Short A, Vessey MP. Intensive Care Society's APACHE II study in Britain and Ireland. II: Outcome comparisons of intensive care units after adjustment for case mix by the American APACHE II method. BMF 1993;307:976-81.

3 Knaus WA, Draper EA, Wagner DP, Zimmerman JE. APACHE II: a severity of disease classification system. Crit Care Med 1985;10:818-29.

4 Horn SD, Bulkley G, Sharkey PD, Chambers AF, Horn RA, Schramm CJ. Interhospital differences in severity of illness: problems for prospective payment based on diagnosis-related groups (DRGS). N Engl f Med 1985;313:20-4.

5 Ridley S, Jackson R, Findlay J, Wallace P. Long term survival after intensive care. $B M f$ 1990;301:1127-30.

6 Zaren B, Bergstrom R, Survival compared to the general population and changes in health status mong intensive care patients. Acta Anaesthesiol Scand 1989;33:6-12.

Wu AW, Rubin HR, Rosen MJ. Are elderly people less responsive to intensive care? $9 \mathrm{Am}$ Geriatr Soc 1990;38:621-7.

8 Knaus WA, Draper EA, Wagner DP, Zimmerman JE. An evaluation of outcome from intensive care in major medical centers. Ann Intern Med 1986;104:410-8.

9 Bion JF, Aitchison TC, Edlin SA, Ledingham IMcA. Sickness scoring and response to treatment as predictors of outcome from critical illness. Intensive Care Med 1988;14:167-72.

10 Dragsted L, Jorgensen J, Jensen N-H, Bonsing E, Jacobsen E, Knaus WA, et al. Interhospital comparisons of patient outcome from intensive care: importance of lead-time bias. Crit Care Med 1989;17:418-22.

11 Knaus WA, Wagner DP, Draper EA, Zimmerman JE, Bergner M, Bastof PG, et al. The APACHE III prognostic system. Risk prediction of hospital mortality for critically ill hospitalized adults. Chest 1991;100:1619-36.

12 Lemeshow S, Teres D, Avrunin JS, Gage RW. Refining intensive care unit outcome prediction by using changing probabilities of mortality. Crit Care Med 1988;16:470-7.

13 Zoltie N, De Dombal FT on behalf of the Yorkshire Trauma Audit Group. The hit and miss of ISS and TRISS. BMF 1993;307:906-9.

\title{
The end of the GMC?
}

\section{The government, not the GMC, is looking at underperforming doctors}

Not with a bang but with a whimper the General Medical Council is slipping into history. Early this week the Department of Health announced that it had set up a group to "update current guidance and procedures relating to the poor performance of doctors." The sparse press release does not mention that the GMC has spent the past four years looking at exactly that subject. Nor does it mention that in the summer the government said it would not be able to find parliamentary time to enact the GMC's proposals. The government is sidelining the GMC and with it the self regulation the profession has enjoyed since 1858 . What's more, it seems to be trying to do so with little public and professional debate.

History has overtaken the GMC, and already we can look back and see the flow of events that has led to its emasculation. The council's central task is to keep a register of doctors and guarantee to the public that everybody on that list is competent and professional. After its inception the council fought for decades to gain control over undergraduate education, but it never gained control over postgraduate education.

Undergraduate education is a mess, and postgraduate education has been "sorted out" by the government through the Calman report. The same Kenneth Calman, the chief medical officer, is to chair the new committee on underperforming doctors.

At the beginning of its 145 year period of influence the GMC paid little attention to registered practitioners who were rogues, but eventually it created disciplinary machinery to remove them from the register. For many years it was criticised for being more concerned about adulterous doctors than incompetent ones, and those complaints are still heard. In the 1970 s the council created a mechanism to deal with sick doctors, and it then began belatedly to debate what to do about incompetent or underperforming doctors.

During this prolonged debate-because the elephantine council works by achieving consensus across the professionthe power of doctors has declined and that of managers increased. The managers have been vocal about underperforming doctors, and a series of high profile disasters, together with tabloid treatment of doctors infected with HIV continuing to practise, have created public concern about the professionalism of doctors. Eventually the politicians have acted. The Labour party has already announced its intention to get rid of the GMC.

Some doctors-particularly some of the bright young things on Dr Calman's committee-may shed no tears over the passing of an atherosclerotic and increasingly anachronistic body, but when a profession loses self regulation it may cease to be a profession. The government may insist that self regulation is not ditched, but it's hard to accept that line. At the very least we need a full debate over self regulation, and at best we need medical leadership that can regain the initiative-for the interest of all.

RICHARD SMITH 